\title{
A Novel Biological Approach to Copper Nanoparticles Synthesis: Characterization and its Application Against Phytopathogenic Fungi
}

Mohamed A. AL Abboud ( $\square$ mohalabboud@hotmail.com )

Jazan University

\section{Research Article}

Keywords: Fungi, copper nanoparticles, characterization , antifungal activity

Posted Date: November 29th, 2021

DOl: https://doi.org/10.21203/rs.3.rs-125001/v2

License: (1) (1) This work is licensed under a Creative Commons Attribution 4.0 International License. Read Full License 


\section{Abstract}

In nanotechnology, fungi have been identified as excellent candidates for the synthesis of nanoparticles, thus presenting a cleaner alternative to produce new materials with a wide range of potential applications in biomedicine and industry. In this respect, A novel biological approach Penicillium olsonii have demonstrated excellent synthesis capacity to produce copper nanoparticles (CuNPs). Their properties were determined by ultraviolet-visible (UV-Vis) absorption spectrum, Fourier transform infrared spectroscopy (FT-IR), and Scanning Electron Microscopy (SEM) images. UV-Vis spectra with characteristic absorption peak was observed at 565nm. Biomolecules mediating the synthesis and stabilizing the nanobactericides was studied with FTIR that showed different functional groups. SEM investigations confirmed that size of CUNPs were varied from 6-26 nm. The antifungal activity of CuNPs was evaluated by testing against three phytopathogenic fungi including Fusarium oxysporum, Fusarium solani and Curvularia curvulatat with growth inhibition $86.25,32.92$ and $68.42 \%$, respectively at 200ppm. F. oxysporum was more affected by CuNPs followed by $C$. curvulata and $F$. solani. The present work demonstrated that it is possible to perform the biogenic synthesis of CuNPs using $P$. olsonii as appropriate fungicide.

\section{Introduction}

Nanoparticles have been synthesized through several physical and chemical processes; however, some chemical methods are costly and inefficient and generate hazardous wastes that are risky for the environment[1]. Therefore, there is an urgent need to develop environmentally friendly biological process for nanoparticle synthesis. Till date, the research in the field of biosynthesis has been mainly focused on $\mathrm{Ag}$ and $\mathrm{Au}$ nanoparticles, and there have been very few reports on the synthesis of $\mathrm{Cu} / \mathrm{CuO}$ nanoparticles[2]. Microorganisms act as a biofactory and can also be used for the synthesis of metal nanoparticles. Fungi, due to their tolerance and bioaccumulationability of metals, are taking the centre-stage of studieson biological metal nanoparticle generation. But a literature review, Varshney et al.[3] revealed only few studies on the biosynthesis of copper nanoparticles (CuNPs) using fungi. Majumber[4] used a fungal species (Fusarium oxysporum) to synthesize CuNPs $(93-115 \mathrm{~nm}$ ) at ambient temperature. Pavani et al.[5] used Aspergillus species of fungus for extracellular synthesis of CuNPs. Penicillium vaksmanii, $P$. aurantiogriseum, and $P$. citrinum have been used for the synthesis of CuNPs[6]. Also dead biomass of Rhodotorula mucilaginosa may considered an efficiently bioprocess, being fast and low-cost to production of CuNPs and also a probably nano-adsorbent of this metal ion in wastewater in bioremediation process[7].CuNPs as well as other nanoparticles have been characterized by ultraviolet-visible absorption spectroscopy, X-ray diffraction[8, scanning electron microscopy $[7,9]$ transmission electron microscopy $[10,11]$ and atomic force microscopy $[12,13]$.

Several nanoparticles are being explored these days for their antimicrobial effects[14], which can be beneficial or harmful, depending on the context. Silver nanoparticles are the most widely studied and used as general antimicrobials $[15,16,17,18]$. However, CuNP have also been reported as effective antimicrobials in several studies $[14,19]$. Copper as a metal exhibit broad-spectrum biocidal activity, and several studies during the last two years found that copper demonstrates remarkable antibacterial activity at the nanoscale[20]. Copper is an essential element for living organisms and may be suitable for biomedical applications [21]. Yoon et al.[10] demonstrated that the antibacterial effects of silver and CuNPs using single representative strain of $E$. coli where the CuNPs showed superior antibacterial activity compared to the silver.

CuNPs showed significant antifungal activity against plant pathogenic fungi, Fusarium oxysporum, Alternaria alternata, Curvularia Iunata and Phoma destructive[22]. At low concentration, CuNPs promoted the growth of the plant pathogenic fungi Botrytis fabae, Fusarium oxysporum f.sp. ciceris, F.oxysporum f.sp. melonis, A. alternate and sporulation of Trichoderma harzianum but at $800 \mathrm{mg} / \mathrm{L}$ completely inhibited mycelial growth of $A$. Alternata[23]. Non-biocidal effect of CuNPs against beneficial microbes was reported and indicates its potential use in the agri-ecosystem[23]. On the other hand if CuNPs used as fungicide, Ramesh et al. [24] reported that CuNPs enhance the germination and growth of some plants at lower concentrations, whereas high concentrations result in retarded growth and show good antimicrobial activity inhibiting the growth of pathogenic bacteria and pathogenic fungi. The purpose of this study was to synthesis CuNPs using a novel biological approach Penicillium olsonii.

\section{Material And Methods}

\section{Screening for Copper Nanoparticles Synthesis}

To explore CuNPs synthesizing agent, samples from soil of peri-urban agricultural areas next to some metal factories in Monoufeya Governorate, Egypt were collected and considered to be source for fungal isolation. Potato Dextrose Agar (PDA) medium was 
amended with different concentration of filtered and sterilized $\mathrm{CuSO}_{4} \cdot 5 \mathrm{H}_{2} \mathrm{O}$ solution ranged from 200 to $1000 \mathrm{ppm}$ and inoculated with particles of soil sample. Followed by incubation at $30^{\circ} \mathrm{C}$ for 7 days. The appeared and recovered isolate at highest concentration was considered as copper-resistant fungi and subjected to a screening process for a biosynthesizes of CuNPs.

\section{Identification of highest copper resistance}

The copper resistant fungus was purified and identified using the keys of Pitt [25] and Domsch et al. [26] based on the macroscopic and microscopic characteristics including rate of colony growth, colony color and shape, reverse color, septation and diameter of mycelium, texture and size of conidia, shape and diameter of conidiophore. The identification was confirmed using molecular tool of PCR according to White et al. [27]. After incubation period 7 days, the growing fungus ( $0.2 \mathrm{~g})$ on PD broth medium was removed and mixed with $300 \mathrm{ul}$ sterile and distilled water in microcentrifuge tube with $95 \mathrm{ul}$ solid tissue buffer (blue) and 10 ul proteinase $\mathrm{K}$. Then mix thoroughly followed by the incubataion at $55^{\circ} \mathrm{C}$ for 2 hours. The reaction mixture was re-mix thoroughly, followed by centrifugation at 12,000 x g for 1 minute. The aqueous supernatant was transfered to a clean tube (300 ul) containing 600 ul Genomic Binding Buffer and mix thoroughly. The mixture was transfer to a Zymo-Spin ${ }^{\mathrm{TM}}$ IIC-XL Column in a Collection Tube and centrifuged at $12,000 \mathrm{xg}$ for 1 minute. Discard the collection tube with the flow through. DNA Pre-Wash Buffer ( $400 \mu \mathrm{l})$ was added to the column in a new collection tube and centrifuged at $12.000 \mathrm{xg}$ for 1 minute. Then700 $\mu \mathrm{g}$-DNA wash buffer was added to the reaction mixture and centrifuge at $(12.000 \mathrm{xg})$ for 1 minute, followed by the empty of the collection tube.Then, $200 \mu \mathrm{lg}$-DNA wash buffer was added and centrifuged at $12.000 \mathrm{xg}$ for 1 minute. Discard the collection tube. Discard the collection tube. Three $\mu$ l elution buffer was added and incubated for 5 minutes, and then centrifuged at $12.000 \mathrm{xg}$ for 1 minute. PCR reaction set-up: Twenty five $\mathrm{mL}$ MyTaq Red Mix, $8 \mathrm{~mL}$ DNA Template , $1 \mathrm{ml}$ (20 Pico mol) Forward Primers, $1 \mathrm{ml}(20$ Pico mol) Reverse Primers, $15 \mathrm{~mL}$ Nuclease Free Water. Thermal Cycler Condition: Initial denaturation at $94^{\circ} \mathrm{C}$ for $6 \mathrm{~min}(1 \mathrm{cycle})$, Denaturation at $94^{\circ} \mathrm{C}$ for $45 \mathrm{~s}$, Annealing at $56^{\circ} \mathrm{C}$ for $45 \mathrm{~s}$, Extension at $72^{\circ} \mathrm{C}$ for $1 \mathrm{~min}$ ( $35 \mathrm{cycle})$, Final Extension at $72^{\circ} \mathrm{C}$ for 5 mins $(1 \mathrm{cycle})$.

\section{Biosynthesis of CuPNs:}

Penicillium olsonii inoculated in potato dextrose (PD) broth media for 7 days at $28^{\circ} \mathrm{C}$. The biomass was harvested after complete incubation by filtering through filter paper followed by repeated washing with distilled water to remove any medium component from the biomass for several times. Three grams of fungus biomass was brought in contact with $100 \mathrm{~mL}$ of sterilized double distilled water with concentration of copper sulfate $(0.02 \mathrm{M})$ to obtain a blue solution and incubated at $25^{\circ} \mathrm{C}$ for 3 days. Control (Without copper) was also run along with the experimental flask.

\section{UV-visible spectroscopic analysis:}

The production CuPNs was confirmed by qualitative testing of supernatant by UV-visible spectrophotometer. One ml of sample supernatant was withdrawn after $24 \mathrm{hr}$ and absorbance was measured by between 300-800 nm at Regional Center For Mycology And Biotechnology, Cairo, Egypt. (RCMB).

\section{Fourier Transform Infrared Spectroscopy (FTIR) and Scanning Electron Microscopy (SEM) analysis:}

The dried powder of CuNPs (2mg) was mixed with $200 \mathrm{mg} \mathrm{KBr} \mathrm{(FTIR} \mathrm{grade)} \mathrm{and} \mathrm{pressed} \mathrm{into} \mathrm{a} \mathrm{pellet.} \mathrm{The} \mathrm{sample} \mathrm{pellet} \mathrm{was} \mathrm{located}$ into the sample holder and FTIR spectra were recorded in the range 450-4000-500 cm-1 in FTIR spectroscopy at a resolution of $4 \mathrm{~cm}^{-1}$. To estimate the size of CuNPs, it characterized by SEM (C Joel Jem-1200 EX II. Acc. Voltage 120 KV. MAG-medium) at RCMB.

\section{Antifungal activity of CuPNs with using Poisoned Food Technique:}

Potato dextrose agar medium (PDA) with different concentration (50, 100, and $200 \mathrm{ppm}$ ) of CuPNs. About $25 \mathrm{ml}$ of the growth medium was poured into each Petri-dish and allowed to solidify. Five $\mathrm{mm}$ disc of 5-day-old culture of the test fungi that provided by RCMB was placed at the center of the Petri-dish and incubated at $28 \pm 2^{\circ} \mathrm{C}$ for 7 days, the growth of fungal colony was measured in millimeter. PDA medium without the CuPNs served as control. 
The fungitoxicity of CuPNs in terms of percentage inhibition of mycelia growth was calculated by using the formula:

$$
\% \text { inhibition radial growth }=\left(\frac{\mathrm{RG} 1-\mathrm{RG} 2}{\mathrm{RG} 1} \mathrm{X} 100\right)
$$

Where, $\mathrm{RG} 1=$ the radial growth at control, $\mathrm{RG} 2=$ the radial growth at treatment [28] .

\section{Result And Discusion}

Initial extensive screen for copper metal resistance fungi, it was discovered that Penicillium olsonii out performed other fungi with regard to fungal growth with copper different metal concentration levels up to $800 \mathrm{ppm}$. The identification of $P$. olsonii funguswas confirmed using molecular characterization, which is based on ITS rDNA (Fig. 1) and applied for CuPNs synthesis. This method of molecular identification of fungi to the species level is primarily based on the variable nature of the DNA's ITS regions [29]. The 18S rRNA sequence of the $P$. olsonii isolate was searched on a database (Basic Local Alignment Search Tool (BLAST)) using multiple sequence alignment (Fig. 1b) with theMEGA6 software. The results of alignment profile, concluded that the P. olsonii 18SrRNA amplicon closely matched other $P$. olsonii strains at more than $99 \%$ ). The constructed phylogenetic relatedness (Fig. 1 ) of the whole sequence of P. olsonii 18S rRNA was compared to the closely related strains from the database (blast.ncbi.nlm.nih.gov/Blast.cgi).

During the present study, the capacity of $P$. olsonii MT635310.1 to synthesize CuNPs was observed where the aqueous $\mathrm{Cu}^{2+}$ ions were reduced during exposure to the culture supernatant of $P$. olsonii MT635310.1. The color of this solution changes from blue to green color after $72 \mathrm{~h}$ of mixing fungus biomass with copper sulfate solution which indicated the formation of CuNPs extracellularly. The present findings are in agreement with the recent findings [30]. The aforementioned studies reported that the appearance of green color color is due to reduction of copper sulfate and its bioconvertion to CuNPs.

The results indicate that the reaction solution has an absorption maximum at about $565 \mathrm{~nm}$ attributed to the surface plasmon resonance band (SPR) of the CuNPs. In general, it has been reported that CuNPs display a surface plasmon peak at 580-590[31]. Although Sudhir et al.[32] demonstrated that the biogenic CuNPs were characterized by UV-Vis spectrophotometer showing a typical resonance (SPR) at about $631 \mathrm{~nm}$ which is specific for CuNPs. CuNPs were studied recently by [30] at 200-1000 nm wavelength range and it has absorbance at 550 to $650 \mathrm{~nm}$.

The size distributions of CuNPs in the aqueous solution was evaluated by SEM images (Figure 2). The synthesized CuNPs by $P$. olsonii were observed by SEM with almost of spherical shape and the particle sizes varied from 6-26 nm. According to Ponnusamy et al. [33] CuNPs size were varied from 5 to $50 \mathrm{~nm}$ in diameter. SEM measurements by Chalandar et al. ${ }^{[34]}$ estimated that extracellular biosynthesis of CuNPs with the diameters $40 \mathrm{~nm}$. It is also reported that Penicillium citrinum, $P$. waksmanii and $P$. aurantiogriseum produced spherical CuNPs of size $90-295 \mathrm{~nm}^{6}$. The size variation may be related to culture conditions and producing microorganism.

FTIR analyses of the nanoparticles biosynthesized using P. olsonii MT635310.1 was recorded (Fig. 3) . The FTIR spectra of the CuNPs biosynthesized revealed the presence of different functional groups. The strong and broad band observed at $3,471 \mathrm{~cm}^{-1}$ indicates the presence of polyphenolic $0-\mathrm{H}$ group and primary amine $0-\mathrm{H}$ band. A narrow band at $1639.73 \mathrm{~cm}^{-1}$, indicates the presence of amide I. While band at $1448.19 \mathrm{~cm}^{-1}$ corresponding to $\mathrm{C}-\mathrm{C}$ stretching aromatic ring, $\mathrm{C}-\mathrm{O}$ stretching carboxylic acid group assigned at 1,243 $\mathrm{cm}-1$, ring, $\mathrm{C}-0$ stretching carboxylic acid group assigned at $1242 \mathrm{~cm}^{-1}$. Cuevas et al. [35] mentioned that bands at 1243 and 1244 $\mathrm{cm}^{-1}$ are designated for bending vibration movements in amides I and amides III. The weak bands at $657 \mathrm{~cm}-1$ may correspond to alkyl halides. These main bands indicate the presence of protein on the surface of the CuNPs and copper oxide nanoparticles. Ore results agreement with previous studies[36,37].

It has been reported that CuNPs act as a fungicide against different species of phytopathogenic fungi such as Fusarium solani, $F$. Oxysporum, Neofusicoccum sp.[38]. CuNPs showed various levels of inhibition on colony growth of $F$. oxysporum, $F$. solani and $C$. curvulata. CuNPs at concentrations of 50, 1000 and $200 \mathrm{ppm}$. Inhibition \% of fungal growth increased with increasing CuNPs concentrations (Table 1 \& fig. 4). These results were agreement with recently result of Chalandar et al.[34] who show that antifungal properties of CuPNs increased by increasing the concentration of nanoparticles to $15 \%$. The optained results showed that the sensitivity of tested fungi to CuNPs depend on species, since F. oxysporum was more sensitive to different levels of CuNPs than Fusarium solani;

Page 4/10 
for example the inhibition \% was 86.25 and 32.92 , respectively at $200 \mathrm{ppm}$. Similar results have been reported for the antifungal activity of CuNPs against different fungal species [38]. Furthermore, similar to present findings, Sudhir et al.[32] reported that Fusarium culmorum was found to be most sensitive to CuPNs followed by F. oxysporum and F. Graminearum. The best chariteria of copper was observed by Ramesh et al.[39] where, the application of CuPNs against plant pathogenic fungi exhibited improvment to plant growth. The previous author estimated the antifungal activity of CuPNs against the pathogenic fungi F.culmorum, F. oxysporum, F. graminearum and Phytophthora infestans beside CuPNs at concentrations below 100 ppm have been reported to enhance germination and growth of some plants. CuNPs not only repress the fungal growth but also inhibit the sporulation process. This may help in elucidating the antifungal mechanisms of CuNPs. The increment of CuNPs concentration was accompained by reduction of sporulation rate that reached to $10.5,20.2$ and $26.5 \%$ at $200 \mathrm{ppm}$ for $F$. oxysporum, $F$. solani and $C$. curvulata, respectively compared to the control (100\%). Sporogenisis of Aspergillus niger has been recently described as sensitive to CuNPs [40]

Morphological of the tested fungi hyphae after exposure to CuNPs was examined in an attempt to understand its inhibition mechanism. Therefore, the underlying mechanism by which CuNPs kill fungi is reflected by changes of fungal morphology (Fig. 5). From the observed micrographs, the hyphae had a bigger and swollen appearance particularly at $200 \mathrm{ppm}$ of CuNPs treatment. Hypae vaculation of F. oxysporum could be clearly observed at $200 \mathrm{ppm}$ of CuNPs. On the other hand, spore size and shape of $F$. solani were dramtecaly changed at high concentration. Chlamydospores were observed in C.curvulata, beside disruption of hyphae. Abd El-Mongy and Abd El-Ghany [41] reported that chlamydospores were formed in fungi under stress conditions. Microscopic observation revealed that the CuNPs clearly damaged the hyphae of Alternaria alternata and Botrytis cinerea [42]. Effect of CuNPs Transmission electron microscopy revealed that CuSO4 and CuNPs treatments encouraged the deformed appearance of the A. niger at 200 ppm and 300 ppm, particularly CuNPs[40].

Table 1

Antifungal activity of different concentrations of CuNPs

\begin{tabular}{|c|c|c|c|c|c|c|c|c|c|}
\hline \multirow{2}{*}{$\begin{array}{l}\text { CuNPs } \\
\text { concentration } \\
\text { ppm }\end{array}$} & \multicolumn{3}{|c|}{ F. oxysporum } & \multicolumn{3}{|l|}{ F. solani } & \multicolumn{3}{|c|}{ C. curvulata } \\
\hline & $\begin{array}{l}\text { Colony } \\
\text { radius } \\
(\mathrm{cm})\end{array}$ & $\begin{array}{l}\text { Growth } \\
\text { Inhibition } \\
\%\end{array}$ & $\begin{array}{l}\text { Sporulation } \\
\%\end{array}$ & $\begin{array}{l}\text { Colony } \\
\text { radius } \\
(\mathrm{cm})\end{array}$ & $\begin{array}{l}\text { Growth } \\
\text { Inhibition } \\
\%\end{array}$ & $\begin{array}{l}\text { Sporulation } \\
\%\end{array}$ & $\begin{array}{l}\text { Colony } \\
\text { radius } \\
(\mathrm{cm})\end{array}$ & $\begin{array}{l}\text { Growth } \\
\text { Inhibition } \\
\%\end{array}$ & $\begin{array}{l}\text { Sporulation } \\
\%\end{array}$ \\
\hline Control & $8.0 \pm 0.1$ & 0.0 & 100 & $8.2 \pm 0.2$ & 0.0 & 100 & $3.8 \pm 0.2$ & 0.0 & 100 \\
\hline 50 & $3.4 \pm 0.2$ & 57.50 & 82.0 & $8.0 \pm 0.1$ & 2.44 & 95 & $3.6 \pm 0.1$ & 5.26 & 88.0 \\
\hline 100 & $1.8 \pm 0.2$ & 77.50 & 39.4 & $7.2 \pm 0.2$ & 12.10 & 25.5 & $2.2 \pm 0.1$ & 42.10 & 50.6 \\
\hline 200 & $1.1 \pm 0.5$ & 86.25 & 10.5 & $5.5 \pm 0.4$ & 32.92 & 20.2 & $1.2 \pm 0.5$ & 68.42 & 26.5 \\
\hline
\end{tabular}

\section{Conclusions}

The present work demonstrated that it is possible to perform the biogenic synthesis of CuNPs using $P$. olsonii as appropriate fungus. It should be mentioned that CuNPS at concentrations of 50,100 and 200 ppm inhibited growth as well as sporogenisis of phytopathogenic fungi.

\section{Declarations}

\section{Conflict of Interests}

The author declare that there is no conflict of interests regarding the publication of this paper.

\section{Research Involving Humans and Animals Statement:}

None. 


\section{Informed Consent:}

None.

\section{Funding statement:}

None

\section{References}

1. Zhang, X. \& Surampalli, R. Y. S.Yan, R.D.Tyagi and 2011. Synthesis of nanoparticles by microorganisms and their application in enhancing microbiological reaction rates.Chemosphere, 82:489-494

2. Thakkar, K. N., Mhatre, S. S. \& Parikh, R. Y. Biological synthesis of metallic nanoparticles." Nanomed. Nanotechnol. Biol. Med, 6 , 257-262 (2010).

3. Varshney, R., Bhadauria, S. \& Gaur, M. S. A review: Biological synthesis of silver and copper nanoparticles. Nano Biomed Eng, 4, 99-106 (2012).

4. Majumber, D. R. Bioremediation: copper Nanoparticles from electronic-waste. Inter J Eng Sci Technol, 4, 4380-4389 (2012).

5. Pavani, K. V., Kumar, N. S. \& Sangameswaran, B. B. Synthesis of lead nanoparticles by Aspergillus species. Pol J Microbiol, 61, 6163 (2012).

6. Honary, S., Barabadi, H., Gharaei-Fathabad, E. \& Naghibi, F. Green synthesis of copper oxide nanoparticles using Penicillium aurantiogriseum, Penicillium citrinum and Penicillium waksmanii. Digest Journal of Nanomaterials and Biostructures, 7 (3), 999 1005 (2012).

7. Salvadori, M. R., Ando, R. A., Oller do Nascimento, C. A. \& Corrêa, B. Intracellular Biosynthesis and Removal of Copper Nanoparticles by Dead Biomass of Yeast Isolated from the Wastewater of a Mine in the Brazilian Amazonia. PLoS, ONE9 (1), e87968 (2014).

8. Sasaki, K. et al. Synthesis of copper nanoparticles within the interlayer space of titania nanosheet transparent films. Journal of Materials Chemistry C, 4, 476-1481 (2016).

9. Park, B. K. et al. Synthesis and size control of monodisperse copper nanoparticles by polyol method. Journal of Colloid and Interface Scie, 311, 417-24 (2007).

10. Yoon, K. Y., Byeon, J., Park, J. H. \& Hwang, J. Susceptibility constants of Escherichia coli and Bacillus subtilis to silver and copper nanoparticles. Science of the Total Environ, 373, 572-75 (2007).

11. Ruparelia, J. P., Chatterjee, A. K., Duttagupta, S. P. \& Mukherji, S. Strain specificity in antimicrobial activity of silver and copper nanoparticles. Acta Biomater, 4, 707-716 (2008).

12. Male, K. B., Hrapovic, S., Liu, Y., Wang, D. \& Luong, J. H. Electrochemical detection of carbohydrates using copper nanoparticles and carbon nanotubes. Analytica Chimica Acta, 516, 35-41 (2004).

13. Chan, G. H., Zhao, J., Hicks, E. M., Schatz, G. C. \& Van Duyne, R. P. Plasmonic properties of copper nanoparticles fabricated by nanosphere lithography. Nano Lett, 7, 1947-1952 (2007).

14. Ren, G. et al. Characterisation of copper oxide nanoparticles for antimicrobial applications. Int J Antimicrob Agents, 33, 587-590 (2009).

15. Abdel Ghany, T. M. Stachybotrys chartarum: a novel biological agent for the extracellular synthesis of silver nanoparticles and their antimicrobial activity. Indonesian J of Biotechnol, 18, 75-82 (2013).

16. Abdel Ghany, T. M., Abdel Rhaman, M. S., Al Abboud, M. A. \& M.M.Alawlaqi Silver nanoparticles biosynthesis by Fusarium moniliforme and their antimicrobial activity against some food-borne bacteria. Mycopath, 11, 1-7 (2013).

17. Abdel Ghany, T. M., Al-Rajhi, A. M. H. \& Al Abboud, M. A. 2017a. Recent advances in green synthesis of silver nanoparticles and their applications: about future directions. A review. BioNanoScience. doi:10.1007/s12668-017-0413-3

18. Abdel Ghany, T. M., Kasem, W. T., Nabih, M. A. \& Ahmed, S. M. Dual synergistic actions of silver nanoparticles with natural products on Ochratoxin A production. Life Sci J, 14, 65-71 (2017b).

19. Jia, B., Mei, Y., Cheng, L. \& J.Zhou, L.Zhang Preparation of copper nanoparticles coated cellulose films with antibacterial properties through one-step reduction. ACS Appl Mater Interfaces, 4, 2897-2902 (2012).

Page 6/10 
20. Durán, N. \& Seabra, A. B. Metallic oxide nanoparticles: state of the art in biogenic syntheses and their mechanisms., " Applied Microbiol and Biotechnol, 95, 275-288 (2012).

21. Rubilar, O. et al. Biogenic nanoparticles: copper, copper oxides, copper sulphides, complex copper nanostructures and their applications. Biotechnol Lett, 35, 1365-1375 (2013).

22. Prachi, K. et al. In vitro antifungal efficacy of copper nanoparticles against selected crop pathogenic fungi. Mater. Lett, 115, 13-17 (2014).

23. Banik, S. \& Pérez-de-Luque, A. 2017. In vitro effects of copper nanoparticles on plant pathogens, beneficial microbes and crop plants.Spanish Journal of Agricultural Research, 15, e1005. https://doi.org/10.5424/sjar/2017152-10305.

24. Ramesh, C. K., Nav, R. P., Ramesh, K. K. \& Praveen, K. Biosynthesis and effects of copper nanoparticles on plants. Environ. Chem. Lett, 15, 233-240 (2017).

25. Pitt, J. I. \& Hocking, A. D. Fungi and Food Spoilage 2nd Edn (Chapman and Hall, Cambridge, 1997).

26. Domsch, K. H., Gams, W. \& Anderson, T. (2007) Compendium of Soil Fungi. 2nd Ed. Eching Germany. IHW-Verlag

27. White, T. J., Bruns, T., Lee, S. \& Taylor, J. (1990). “Amplification and direct sequencing of fungal ribosomal RNA genes for phylogenetics,"in:PCR Protocols: AGuide to Methods and Applications, M. A. Innis, D. H.Gelfand, J. J. Sninsky, and T. J. White (eds.),Academic Press, New York, NY,pp.315-322

28. Singh, J. \& Tripathi, N. N. N.N 1999. Inhibition of storage fungi of blackgram (Vigna mungo L.) by some essential oils.Flavour Fragrance J., 14:1-4

29. Delgado-Serrano, L., Restrepo, S., Bustos, J. R., Zambrano, M. M. \& andAnzola, J. M. (2016). "Mycofier: A new machine learningbased classifier for fungal ITS sequences,"BioMed Central Res.Notes2016(9), Article ID 402,8 pp.DOI: 10.1186/s13104-016-2203-3

30. Mohamed, T. et al. Allam and Nashwa Elshaer 2020. Ecofriendly Synthesis and Insecticidal Application of Copper Nanoparticles against the Storage Pest Tribolium castaneum. Nanomaterials, 10, 587 (2020).

31. Soomro, R. A., Hussain, S. T. \& Memon, N. Synthesis of air stable copper nanoparticles and their use in catalysis. Advanced Materials Letters, 5, 191-198 (2014).

32. Sudhir, S., Avinash, P. L., Aniket, G. \& Mahendra, R. Green synthesis of copper nanoparticles by Citrus medicaLinn. (Idilimbu) juice and its antimicrobial activity. World Journal of Microbiology and Biotechnol, 31, 865-873 (2015).

33. Ponnusamy, P., Kolandasamy, M., Viswanathan, E. \& Balasubramanian, M. G. Antifungal activity of biosynthesised copper nanoparticles evaluated against red root-rot disease in tea plants. Journal of Experimental Nanosci, 11, 13:131019-1031 (2016).

34. Chalandar, H., E, H. R., Ghorbani, H., Attar, S. A. \& Alavi Antifungal Effect of Copper and Copper Oxide Nanoparticles Against Penicillium on Orange Fruit. Biosci Biotechnol Res Asia, 14, 279-284 (2017).

35. Cuevas, R., Durán, N., Diez, M. C., Tortella, G. R. \& Rubilar, O. Extracellular Biosynthesis of Copper and Copper Oxide Nanoparticles by Stereum hirsutum, a Native White-Rot Fungus from Chilean Forests. Journal of Nanomaterials Volume 2015, Article ID, 789089, 7 (2015).

36. Kooti, M. \& L.Matouri Fabrication of nanosized cuprous oxide using fehling's solution., " Scientia Iranica, 17, 73-78 (2010).

37. Hosseini, M. R., Schaffie, M., Pazouki, M., Darezereshki, E. \& Ranjbar, M. Biologically synthesized copper sulfide nanoparticles: production and characterization. Materials Science in Semiconductor Processing, 15, 222-225 (2012).

38. Pariona, N. et al. 2019. Green-synthesized copper nanoparticles as a potential antifungal against plant pathogens. RSC Adv., 2019, 9, 18835-18843. DOI: 10.1039/c9ra03110c

39. Ramesh, C. K., Nav, R. P., Ramesh, K. K. \& Praveen, K. Copper Nanoparticles in Agriculture: Biological Synthesis and Antimicrobial Activity. Nanoscience in Food and Agriculture, 3, 129-143 (2016).

40. Abdel Ghany, T. M. et al. Shater 2020.Impact of Copper and Its Nanoparticles on Growth, Ultrastructure, and Laccase Production of Aspergillus niger using Corn Cobs Wastes.BioResources15(2):3289-3306

41. Abd El-Mongy, M. \& Abd El-Ghany, T. M. Field and laboratory studies for evaluating the toxicity of the insecticide Reldan on soil fungi. Int. Biodeterior. Biodegrad, 63, 383-388 (2009).

42. Sahar, M. \& Ouda 2014. Antifungal Activity of Silver and Copper Nanoparticles on Two Plant Pathogens, Alternaria alternata and Botrytis cinerea. Research Journal of Microbiology, 9: 34-42. DOI: 10.3923/jm.2014.34.42

\section{Figures}

Page $7 / 10$ 


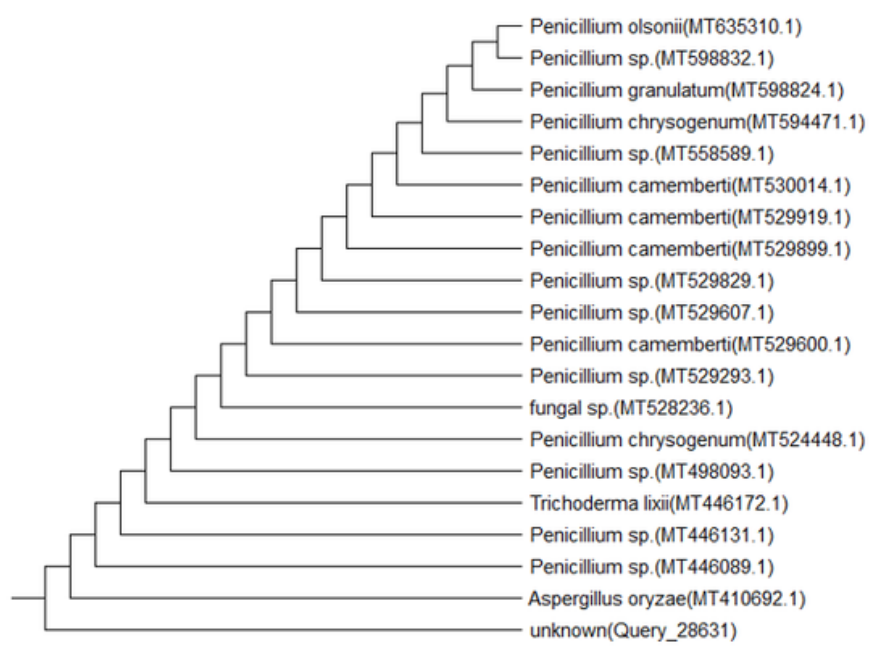

a

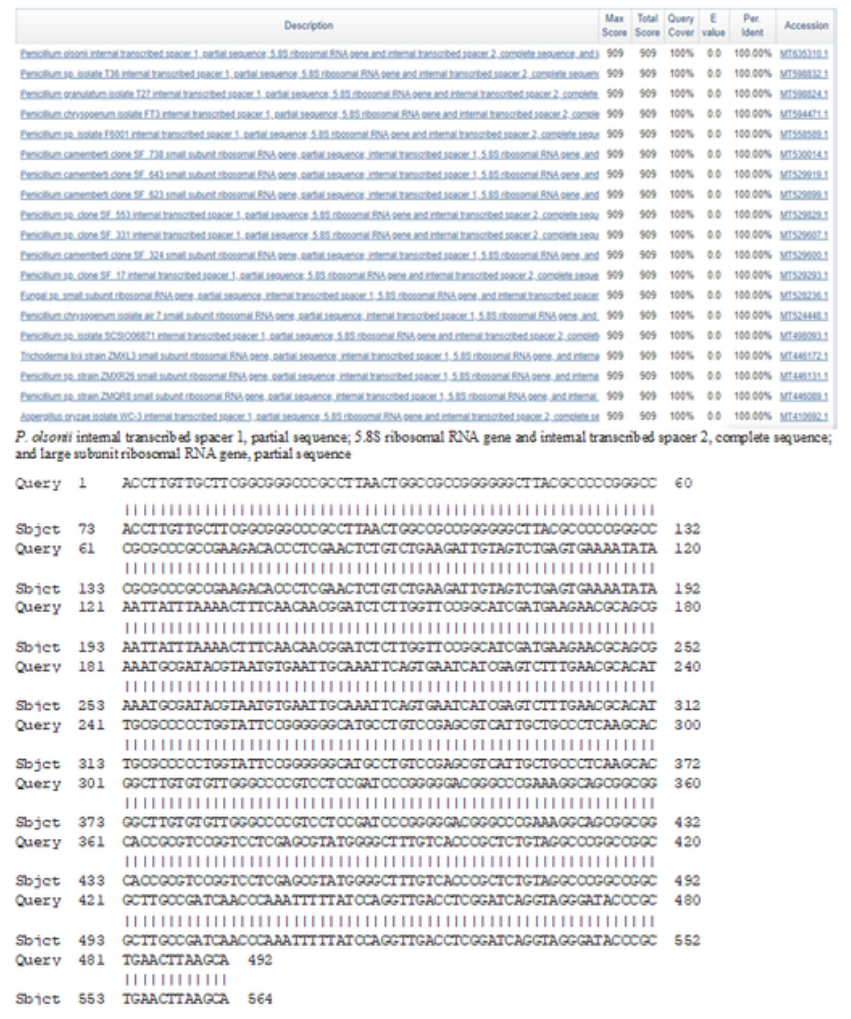

b

\section{Figure 1}

a. Phylogenetic relationships amoung the P. olsonii strain MT635310.1 and the ITS sequences of closely related fungal strains retrieved from the NCBIGenBank database b. Nucleotide sequence alignment of Penicillium olsonii MT635310.1

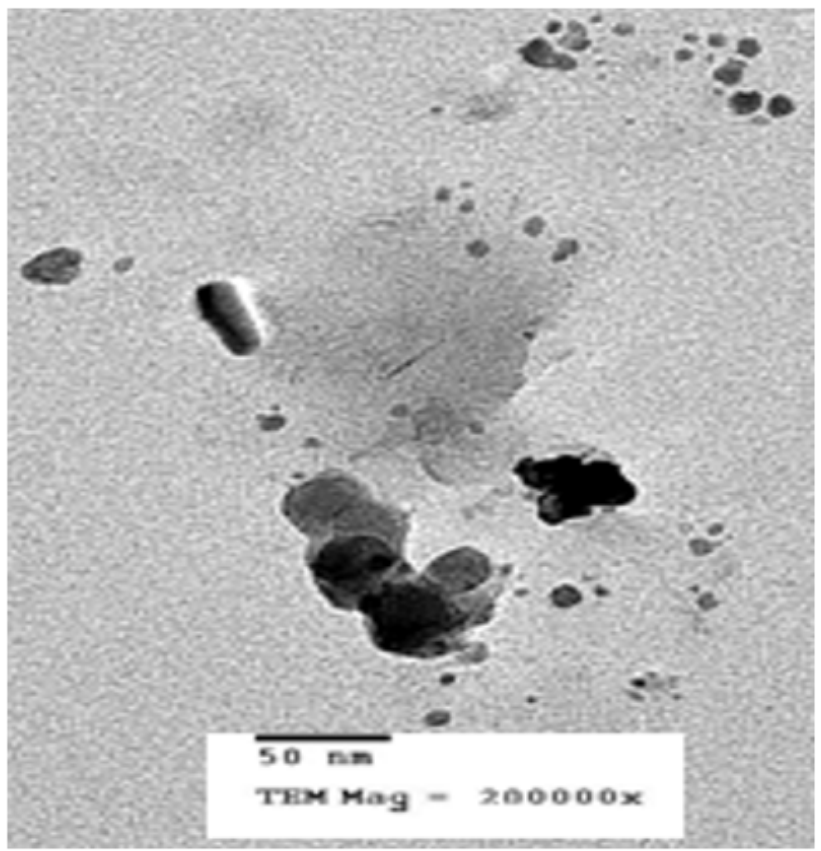

\section{Figure 2}

Scanning electron microscope of detected CuNPs produced by P. olsonii MT635310.1 


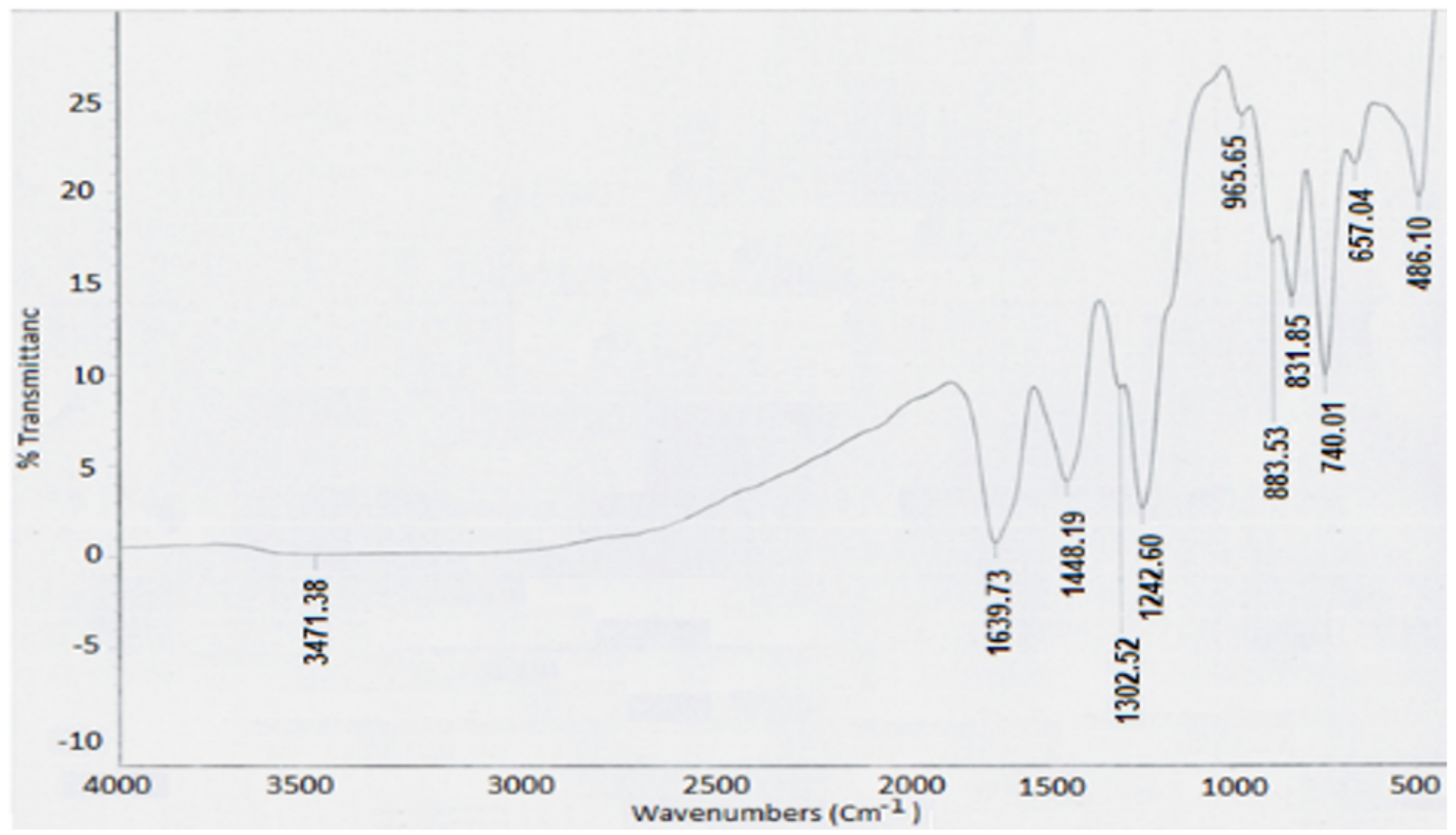

\section{Figure 3}

FTIR spectrum of CuNPs formed after $72 \mathrm{~h}$ of incubation of the biomass of P. olsonii MT635310.1
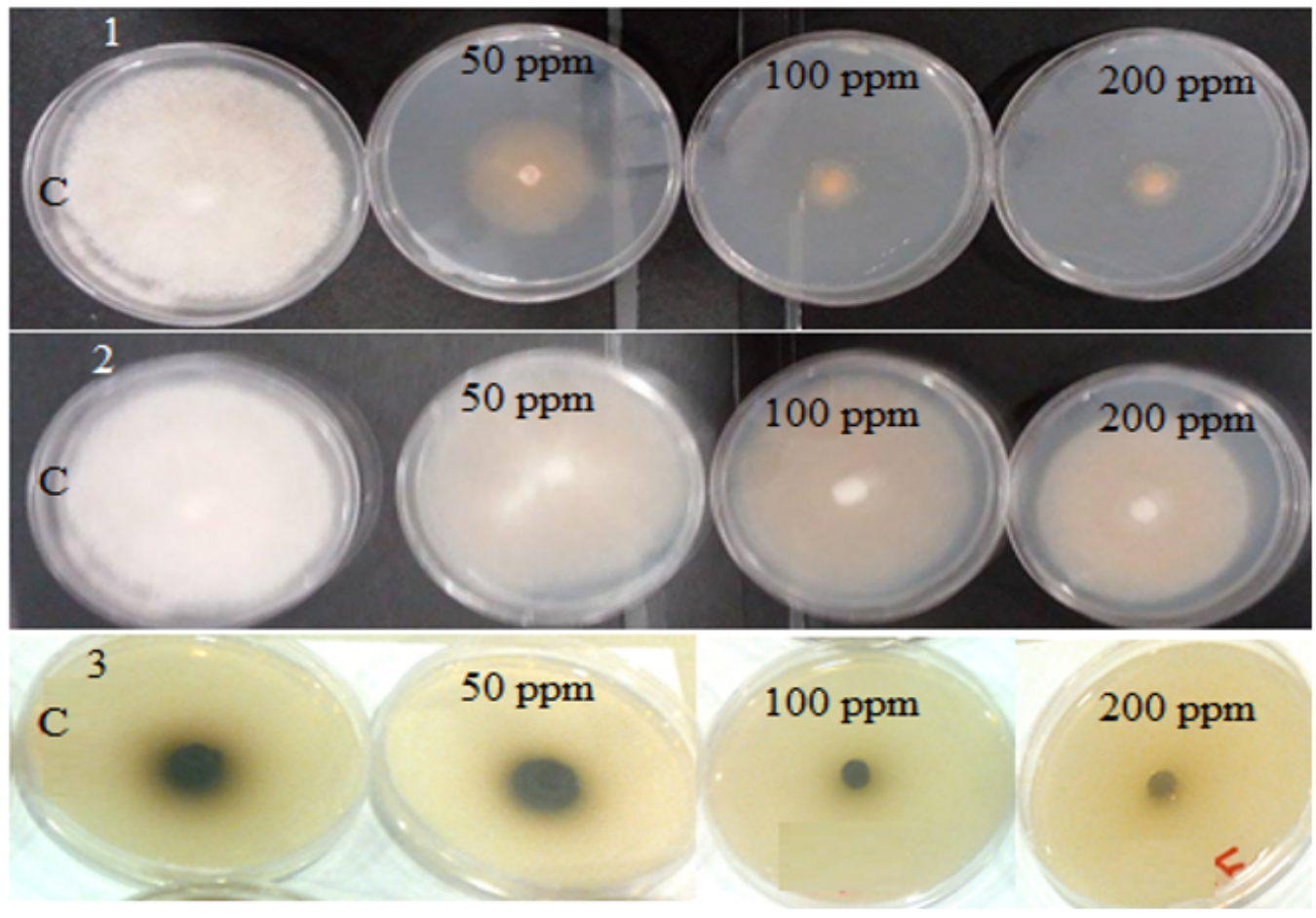

Figure 4

Antifungal activity of different concentrations of CuNPs against F. oxysporum (1), F. solani (2) and C. curvulata 


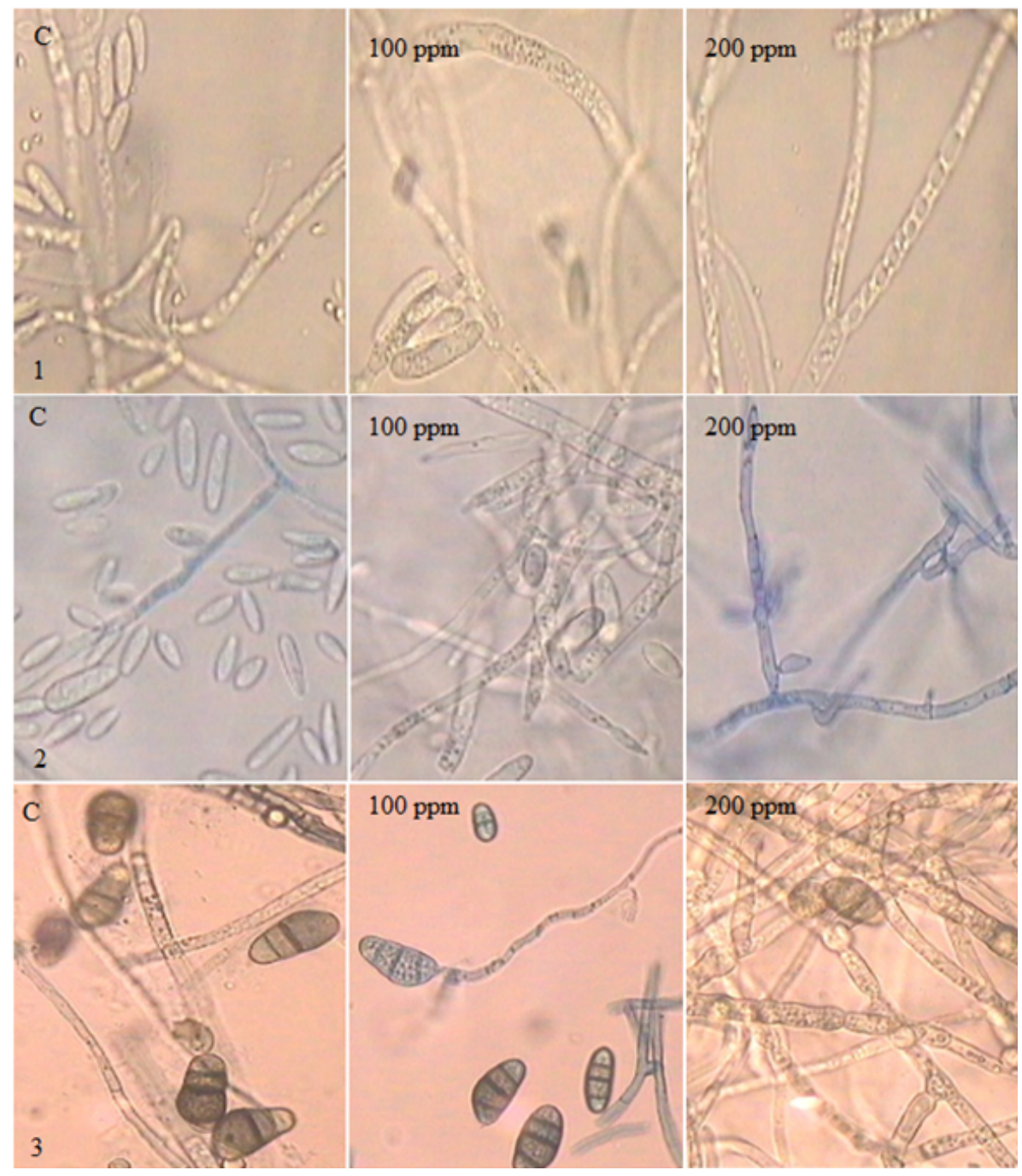

\section{Figure 5}

Morphological charaterization of at different concentrations of F. oxysporum (1), F. solani (2) and C. curvulata 